\title{
Article
}

\section{Versatility of Boron-Mediated Coupling Reaction of Oxetanes and Epoxides with CO2: Selective Synthesis of Cyclic Carbonates or Linear Polycarbonates}

Cheng-Jian Zhang, Shao-Qi Wu, Senthil Boopathi, XingHong Zhang, Xin Hong, Yves Gnanou, and Xiao-Shuang Feng

ACS Sustainable Chem. Eng., Just Accepted Manuscript • DOI: 10.1021/

acssuschemeng.0c04768 - Publication Date (Web): 05 Aug 2020

Downloaded from pubs.acs.org on August 5, 2020

\section{Just Accepted}

\begin{abstract}
"Just Accepted" manuscripts have been peer-reviewed and accepted for publication. They are posted online prior to technical editing, formatting for publication and author proofing. The American Chemical Society provides "Just Accepted" as a service to the research community to expedite the dissemination of scientific material as soon as possible after acceptance. "Just Accepted" manuscripts appear in full in PDF format accompanied by an HTML abstract. "Just Accepted" manuscripts have been fully peer reviewed, but should not be considered the official version of record. They are citable by the Digital Object Identifier (DOI®). "Just Accepted" is an optional service offered to authors. Therefore, the "Just Accepted" Web site may not include all articles that will be published in the journal. After a manuscript is technically edited and formatted, it will be removed from the "Just Accepted" Web site and published as an ASAP article. Note that technical editing may introduce minor changes to the manuscript text and/or graphics which could affect content, and all legal disclaimers and ethical guidelines that apply to the journal pertain. ACS cannot be held responsible for errors or consequences arising from the use of information contained in these "Just Accepted" manuscripts.
\end{abstract}




\section{Versatility of Boron-Mediated Coupling Reaction of \\ Oxetanes and Epoxides with $\mathrm{CO}_{2}$ : Selective}

Synthesis of Cyclic Carbonates or Linear

\section{Polycarbonates}

Cheng-Jian Zhang ${ }^{a, b}$, Shao-Qi Wuc ${ }^{c}$, Senthil Boopathi ${ }^{b}$, Xing-Hong Zhang ${ }^{a *}$, Xin Hong ${ }^{c *}$, Yves

Gnanou $^{b *}$, and Xiao-Shuang Feng ${ }^{b *}$

${ }^{a}$ MOE Key Laboratory of Macromolecular Synthesis and Functionalization, Department of Polymer Science and Engineering, Zhejiang University, Hangzhou 310027, China

b Physical Sciences and Engineering Division, King Abdullah University of Science and Technology (KAUST), Thuwal 23955, Saudi Arabia

${ }^{c}$ Department of Chemistry, Zhejiang University, Hangzhou 310027, China

\section{Corresponding Authors}

Xing-Hong Zhang*, xhzhang@zju.edu.cn;

Xin Hong*, hxchem@zju.edu.cn;

Yves Gnanou*, yves.gnanou@kaust.edu.sa;

Xiao-Shuang Feng*, xiaoshuang.feng@kaust.edu.sa. 


\begin{abstract}
Achieving simultaneously high selectivity and high rate in the coupling reaction of $\mathrm{CO}_{2}$ with poorly reacting oxetanes remains a major challenge. Here is described the selective and nearly quantitative conversion of the coupling reaction of oxetanes with $\mathrm{CO}_{2}$ into six-membered cyclic organic carbonates (COCs) when a binary metal-free system composed of commercially available alkyl borane and onium iodide salts is used under 10 bar $\mathrm{CO}_{2}$ pressure between 90 and $110{ }^{\circ} \mathrm{C}$. Kinetic investigations provide quantitatively the enthalpy and entropy of activation $\left[\Delta \mathrm{H}^{\ddagger}=6.7 \pm\right.$ $1.2 \mathrm{kcal} / \mathrm{mol}$ and $\left.\Delta \mathrm{S}^{\ddagger}=-57 \pm 4 \mathrm{cal} /(\mathrm{mol} \cdot \mathrm{K})\right]$ of the back-biting, cyclic formation reaction. In addition to forming borate complexes with the anions responsible for the $\mathrm{CO}_{2}$ /oxetane coupling reaction, these alkyl boranes activate the cyclic ethers as unambiguously confirmed by DFT studies. Upon selecting onium salts other than iodide-based ones, in particular those with poor leaving ability, the process is driven towards chain growth and the formation of linear polycarbonates. This metal-free system also exhibits both versatility and an activity comparable to that of metal catalysts (turnover frequency values of $14-124 \mathrm{~h}^{-1}$ ) for the synthesis of various fivemembered COCs from epoxides and $\mathrm{CO}_{2}$.
\end{abstract}

KEYWORDS: carbon dioxide $\bullet \mathrm{CO}_{2}$ fixation $\bullet$ coupling reaction $\bullet$ organocatalysis $\bullet$ alkyl borane

\title{
INTRODUCTION
}

The development of synthetic methods utilizing $\mathrm{CO}_{2}$ as a renewable carbon feedstock for producing value-added products has been a long-term goal for scientists since $\mathrm{CO}_{2}$ is abundant, recyclable, and nontoxic. ${ }^{[1-7]}$ Of particular interest are the synthesis of cyclic organic carbonates 
(COCs) via cycloaddition of $\mathrm{CO}_{2}$ to cyclic ethers and that of linear polycarbonates synthesized by copolymerization of $\mathrm{CO}_{2}$ with the same cyclic ethers. ${ }^{[8-12]} \mathrm{COCs}$ have been applied in many areas such as electrolytes, ${ }^{[13]}$ highly boiling polar solvents, ${ }^{[14]}$ and chemical intermediates in the synthesis of pharmaceuticals. ${ }^{[15-17]}$ On the other hand, linear polycarbonates have been tailored for the manufacture of polyols used in a wide range of applications. ${ }^{[18,19]}$ When comparing cyclic ethers that can be coupled with $\mathrm{CO}_{2}$, four-membered oxetanes are more challenging substrates than three-membered epoxides because of their much lower reactivity, as revealed by previous studies. ${ }^{[8,20-22]}$ Unlike five-membered COCs derived from the cycloaddition of $\mathrm{CO}_{2}$ to epoxides that are very stable, six-membered COCs obtained by the coupling of oxetanes with $\mathrm{CO}_{2}$ can undergo ring-opening polymerization and afford highly valuable polycarbonates. Being thermodynamically less stable than the resulting polymer, achieving a high cyclic versus linear selectivity is a real challenge in the case of six-membered COCs, as depicted in Scheme 1. ${ }^{[23-28]}$

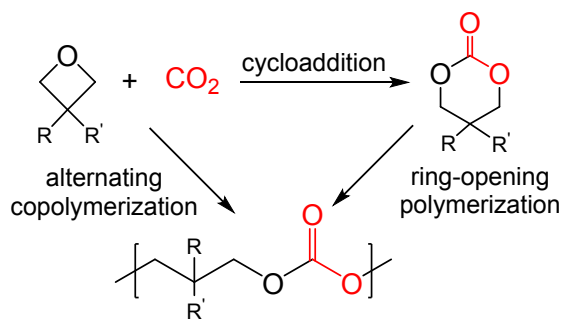

Scheme 1. Involved reactions in oxetanes $/ \mathrm{CO}_{2}$ coupling reaction.

Notwithstanding, a few examples of the selective formation of six-membered COCs by $\mathrm{CO}_{2} /$ oxetane coupling using metal catalysis have been described in the literature. The group of Kleij developed Al(III)- and Fe(III)-based amino-(triphenolate) catalysts for such coupling reactions, ${ }^{[29-31]}$ and achieved a high conversion $(95 \%)$ of trimethylene oxide (TMO) into trimethylene carbonate (TMC) using their Al(III)-based catalyst without observing the formation of polycarbonate. ${ }^{[31]}$ The Darensbourg group also reported the formation of TMC with limited 
selectivity $(<87 \%)$ from their $\mathrm{Co}$ (III) salen complexes used in the presence of onium salt as a cocatalyst. ${ }^{[23]}$ The same group resorted to $\mathrm{VO}(\mathrm{acac})_{2}$ catalyst combined with an onium salt for the catalysis of $\mathrm{TMO} / \mathrm{CO}_{2}$ coupling reaction and obtained a TMC selectivity of $99 \% \cdot{ }^{[32]}$ These Co(III) salen complexes that are characterized by complex ligands requiring multiple synthesis steps, the prior coordination of oxetane to metal complex facilitates its electrophilic attack and the ringopening of the four-membered cyclic ether. Oxetanes bearing more sterically hindered substrates generally exhibit a lower reactivity than TMO, and thus their coupling with $\mathrm{CO}_{2}$ met with little success yielding the corresponding COCs with low yields and poor selectivities.

In the front of aliphatic polycarbonates generated by the copolymerization of oxetanes with $\mathrm{CO}_{2}$, the literature is scarce. ${ }^{[20-25]}$ This reaction has been little investigated but it has been shown in most cases that two mechanisms occur simultaneously: formation of TMC as a byproduct which is eventually ring-opened and concomitantly regular copolymerization yielding alternate enchainment of oxetane and $\mathrm{CO}_{2}$. In more recent additions, the literature provides examples of linear oligocarbonates obtained by organocatalysis. For instance, Detrembleur and coworkers demonstrated that in the presence of fluorinated alcohols and onium salts the coupling of $\mathrm{CO}_{2}$ with oxetane first produced TMC which can then be ring-opened in situ under $10-100$ bar $\mathrm{CO}_{2}$ at 130 ${ }^{0} \mathrm{C}$ to afford $\alpha, \omega$-oligocarbonates with average molecular weights of around $2.0 \mathrm{~kg} / \mathrm{mol} .{ }^{[20]} \mathrm{In}$ a series of two contributions, Coulembier, Dove and coworkers resorted to an organocatalytic system made of $\mathrm{I}_{2}$ and oniums salts to selectively synthesize TMC at temperatures below $55{ }^{\circ} \mathrm{C}$ (96 hours of reaction in DMF and under 30 bar $\mathrm{CO}_{2}$ for a TMC yield of $86 \%$ with a selectivity of $93 \%$ ) and linear polycarbonates above $105{ }^{\circ} \mathrm{C}$ (96 hours of reaction under 30 bar of $\mathrm{CO}_{2}$ for a polycarbonate yield of around $80 \%$ and about $8 \%$ ether linkages). ${ }^{[21,22]}$ In the light of the above literature survey, it appears that designing an initiating system or a synthetic method that can 
efficiently and selectively produce either 6-membered COCs or linear polycarbonates by coupling oxetanes with $\mathrm{CO}_{2}$ is still a challenge to overcome.

In a recent contribution to the vast literature on linear polycarbonates, we demonstrated that borate complexes obtained by reaction of an alkyl borane with a metal-free anionic initiator bring about the copolymerization of epoxides with $\mathrm{CO}_{2} \cdot{ }^{[33]}$ Provided alkyl borane is added in excess to activate the epoxides, such copolymerizations exhibit selectivity and activity comparable to those catalyzed by transition metal complexes. Besides the above example, borane-based Lewis acids are extensively used as activators in organic synthesis, ${ }^{[34-36]}$ and promote the activation of small molecules when associated with Lewis bases in frustrated Lewis pairs. ${ }^{[37-39]}$
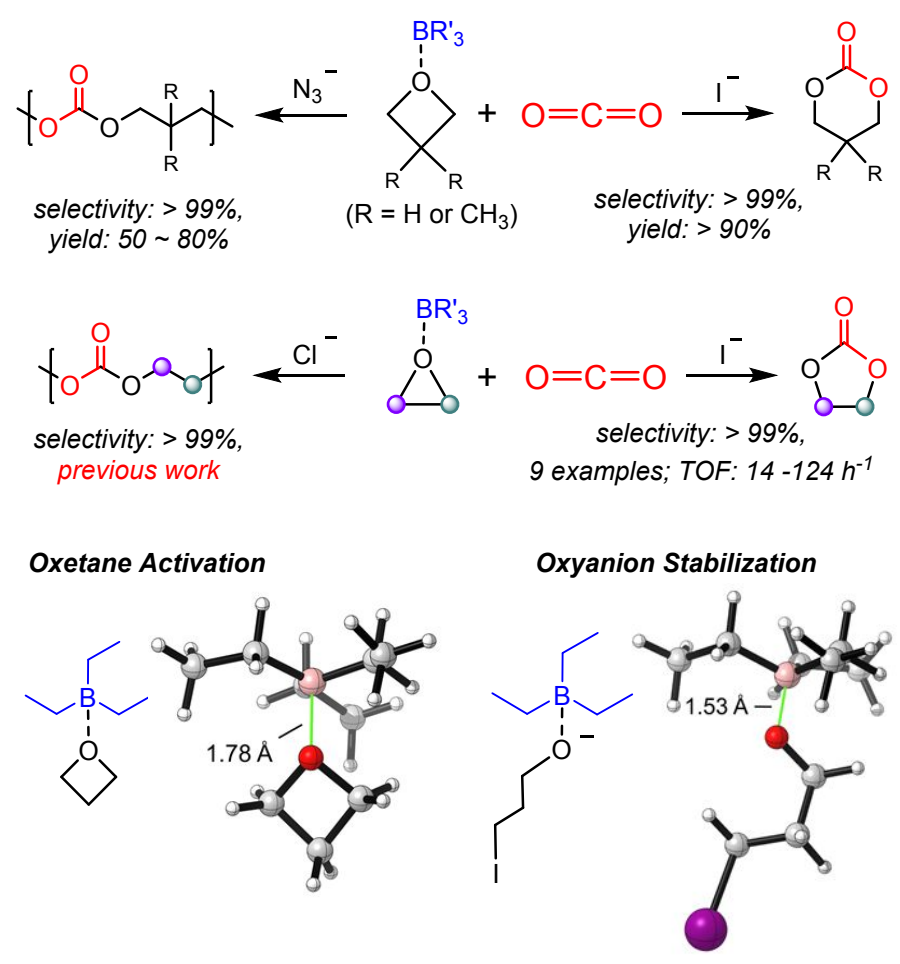

Scheme 2. Selectively coupling of cyclic ethers with $\mathrm{CO}_{2}$ using trialkyl borane and halide or pseudohalide salts. 
In this work, we used commercially available alkyl boranes such as triethyl borane (TEB) and tributyl borane (TBB) to mediate the coupling of $\mathrm{CO}_{2}$ with oxetanes and epoxides in the presence of nucleophilic quaternary ammonium/phosphonium halide and pseudohalide salts (Scheme 2). Depending upon the halide present in such quaternary ammonium salts, the coupling of $\mathrm{CO}_{2}$ with oxetanes affords nearly quantitatively and with complete selectivity either six-membered COCs or linear polycarbonates within $8-14 \mathrm{~h}$ and under mild conditions $\left(10\right.$ bar $\left.\mathrm{CO}_{2}, 90-110{ }^{\circ} \mathrm{C}\right)$. The computational study confirms that alkyl boranes not only activate oxetane but also stabilize the oxyanion intermediate in the form of a borate complex. This work provides the example of a versatile and efficient metal-free process that gives selectively access either to six-membered COCs or to linear polycarbonates from $\mathrm{CO}_{2}$ and (substituted) oxetanes by selection of the appropriate halide initiator.

\section{RESULTS AND DISCUSSION}

\section{Selective synthesis of TMC from $\mathrm{CO}_{2}$ and TMO.}

We initially employed TEB and TBB in association with various nucleophiles to mediate the $\mathrm{TMO} / \mathrm{CO}_{2}$ coupling reaction under 10 bar $\mathrm{CO}_{2}$ pressure at $90{ }^{\circ} \mathrm{C}$. The trialkylborane or the nucleophile alone cannot catalyze (initiate) the $\mathrm{TMO} / \mathrm{CO}_{2}$ coupling reaction under these conditions (entries 1 and 2 in Table 1). It was observed that both the rate of reaction and the linear versus cyclic selectivity greatly depend upon the halogen or pseudohalogen of these quaternary ammonium/phosphonium compounds (Table 1). For instance, with a [TMO]/[TEB]/[nucleophile ] feed ratio of $100 / 5 / 1$, the nucleophiles being in this case iodine salts of quaternary ammonium or phosphonium $\left(\mathrm{NBu}_{4} \mathrm{I}\right.$ and $\left.\mathrm{PPh}_{4} \mathrm{I}\right)$, a high activity (TMO conversions of $94 \%$ and $95 \%$, respectively) and complete selectivity ( $>99 \%$ ) were observed toward the formation of TMC (entries 3 and 4 in 
Table 1) within $8 \mathrm{~h}$, as determined by the ${ }^{1} \mathrm{H}$ NMR spectra (Figures $\mathrm{S} 1$ and S2). Under the same conditions, the use of bromide-containing nucleophiles $\left(\mathrm{NBu}_{4} \mathrm{Br}\right.$, $\mathrm{NOCt}_{4} \mathrm{Br}$, and $\left.\mathrm{PPh}_{4} \mathrm{Br}\right)$ resulted in high activity as well with TMO conversions in the range of $97-99 \%$, and a moderate TMC selectivity of $84-90 \%$ (entries 5-7 in Table 1, Figures S3 and S4). In contrast, $\mathrm{NBu}_{4} \mathrm{Cl}_{2} \mathrm{PPh}_{4} \mathrm{Cl}$, and PPNCl exhibited moderate activity with TMO conversions of $52-63 \%$, and poor TMC selectivities of $15-65 \%$ (entries 8-10 in Table 1, Figures S5 and S6). The combination of TBB with iodine-containing nucleophiles also resulted in a high TMO conversion of $93 \%$ and a high TMC selectivity of $>99 \%$ (entries 11 and 12 in Table 1 ) when used in $\mathrm{TMO} / \mathrm{CO}_{2}$ coupling reaction. Another advantage of using trialkyl boranes is that they can be readily oxidized and hydrolyzed when exposed to air and can be very conveniently separated from TMC or linear polycarbonates (Figure S7).

Table 1. Coupling reaction of trimethylene oxide with $\mathrm{CO}_{2}$ using trialkyl boranes with various nucleophiles. ${ }^{[a]}$

\begin{tabular}{|c|c|c|c|c|c|c|c|c|}
\hline \multirow{2}{*}{ entry } & \multirow{2}{*}{ nucleophile } & \multirow{2}{*}{ borane } & \multirow{2}{*}{$\begin{array}{l}\text { conv } \\
(\%)^{[b]}\end{array}$} & \multicolumn{2}{|c|}{ selectivity $(\%)^{[\mathrm{c}]}$} & \multirow{2}{*}{$\begin{array}{c}\text { carbonate } \\
\text { /ether }^{[c]}\end{array}$} & \multirow{2}{*}{$\begin{array}{c}M_{\mathrm{n}} \\
(\mathrm{g} / \mathrm{mol})^{[\mathrm{d}]}\end{array}$} & \multirow{2}{*}{$\bigoplus^{[\mathrm{d}]}$} \\
\hline & & & & TMC & poly(TMC) & & & \\
\hline 1 & $\mathrm{NBu}_{4} \mathrm{I}$ & - & 0 & - & - & - & - & - \\
\hline 2 & - & TEB & 0 & - & - & - & - & - \\
\hline 3 & $\mathrm{NBu}_{4} \mathrm{I}$ & TEB & 94 & $>99$ & - & - & - & - \\
\hline 4 & $\mathrm{PPh}_{4} \mathrm{I}$ & TEB & 95 & $>99$ & - & - & - & - \\
\hline 5 & $\mathrm{NBu}_{4} \mathrm{Br}$ & TEB & 98 & 84 & 16 & - & - & - \\
\hline 6 & $\mathrm{NOCt}_{4} \mathrm{Br}$ & TEB & 97 & 90 & 10 & - & - & - \\
\hline 7 & $\mathrm{PPh}_{4} \mathrm{Br}$ & TEB & $>99$ & 84 & 16 & - & - & - \\
\hline 8 & $\mathrm{NBu}_{4} \mathrm{Cl}$ & TEB & 52 & 15 & 85 & $92 / 8$ & 3500 & 1.4 \\
\hline 9 & $\mathrm{PPh}_{4} \mathrm{Cl}$ & TEB & 58 & 65 & 35 & - & - & - \\
\hline 10 & $\mathrm{PPNCl}$ & TEB & 63 & 21 & 79 & $93 / 7$ & 4100 & 1.6 \\
\hline 11 & $\mathrm{NBu}_{4} \mathrm{I}$ & $\mathrm{TBB}$ & 93 & $>99$ & - & - & - & - \\
\hline
\end{tabular}




$\begin{array}{ccccccccc}12 & \mathrm{PPh}_{4} \mathrm{I} & \mathrm{TBB} & 93 & >99 & - & - & - & - \\ 13[\mathrm{e}] & \mathrm{NBu}_{4} \mathrm{~N}_{3} & \text { TEB } & 73 & - & >99 & 95 / 5 & 6800 & 1.5 \\ 144^{[\mathrm{f}]} & \mathrm{NBu}_{4} \mathrm{~N}_{3} & \text { TEB } & 84 & - & >99 & 94 / 6 & 8000 & 1.5\end{array}$

[a] Reactions were run at $90{ }^{\circ} \mathrm{C}$ under 10 bar $\mathrm{CO}_{2}$ for $8 \mathrm{~h}, \mathrm{TMO} /$ trialkyl borane/nucleophile molar ratio of 100/5/1, no solvent, $\mathrm{PPNCl}=$ bis(triphenylphosphine)iminium chloride; [b] $\mathrm{TMO}$ conversion; [c] Selectivity of TMC and poly(TMC) and carbonate/ether content ratio in poly(TMC), determined by ${ }^{1} \mathrm{H}$ NMR spectra; [d] Determined by GPC in tetrahydrofuran (THF) with polystyrene standards; [e] For $24 \mathrm{~h}$; [f] For $72 \mathrm{~h}$.

According to the results shown in Table 1, the activity and selectivity orders of these nucleophiles toward the formation of $\mathrm{TMC}$ are $\mathrm{I}^{-} \approx \mathrm{Br}^{-}>\mathrm{Cl}^{-}$and $\mathrm{I}^{-}>\mathrm{Br}^{-}>\mathrm{Cl}^{-}$, respectively. The reason can be ascribed to the differences in the nucleophilic character and polarization of these halogen ions, and the stability of TMC under the reaction conditions. Since the ionic radius of $\mathrm{Cl}^{-}$, $\mathrm{Br}^{-}$and $\mathrm{I}^{-}$are gradually increasing, their polarization and leaving ability increase accordingly. Compared to the halogen ions, the type and the size of the quaternary ammonium and phosphonium counter cations associated with the investigated nucleophiles have little effect on both the rate and selectivity of the coupling reaction. By themselves, these onium salts are unable to react with TMO and open the four-membered ring or to react with $\mathrm{CO}_{2}$ under similar conditions. Upon addition of TEB or TBB, the iodide anion attacks the borane-activated TMO, leading to the formation of a growing oxyanion capped with TEB or TBB. Both anion and cation are thereby separated by a relatively long distance and only weakly interact. The TEB or TBB-capped oxyanion with one unit of oxetane then reacts with $\mathrm{CO}_{2}$. The resulting borate-carbonate active species may then show a preference for back-biting reactions if the anion used as initiator is known to be a good leaving group. In the opposite case when the anion that served as initiator is a fair leaving group, the above borate-carbonate active species will give preference to propagation and to the ring-opening of 
oxetanes. The chemoselectivity results and the anion dependence of this system are totally different from those catalyzed by the metallic salen complexes. ${ }^{[23-25]}$ In the latter case, whatever halides associated with these complexes linear poly(TMC) were obtained as major products due to the concomitant ring-opening polymerization of TMC formed.

\section{Kinetic investigation of $\mathrm{TMO} / \mathrm{CO}_{2}$ coupling to TMC.}

In an effort to examine more quantitatively the coupling of $\mathrm{TMO}$ with $\mathrm{CO}_{2}$ triggered by the system made of TEB and the above-mentioned onium salts, we monitored this reaction by in situ infrared spectroscopy. Toluene was used as a solvent and introduced in a quantity that allowed to immerce the probe of the IR instrument underneath. First, the reaction was carried out at $90{ }^{\circ} \mathrm{C}$ with TEB/ $\mathrm{NBu}_{4} \mathrm{I}$ as the catalyst. Figure 1a shows the infrared traces indicating the formation of TMC as a function of time. Figure $1 \mathrm{~b}$ shows the profile of TMC production, obtained through monitoring the infrared absorption in the region at $1770-1750 \mathrm{~cm}^{-1}$ attributed to the $\mathrm{C}=\mathrm{O}$ bond of TMC. A control experiment carried out in the presence of $\mathrm{TEB} / \mathrm{NBu}_{4} \mathrm{Br}$ used as catalyst suggests that the infrared absorptions of $\mathrm{C}=\mathrm{O}$ bonds of both $\mathrm{TMC}$ and poly(TMC) overlap in a certain region (Figure S8). Figure 1c illustrates the linear variation of $\ln \left(A_{\infty}-A_{t}\right) v s$. time, where $A$ is the absorbance of TMC, providing a first-order rate constant $(k)$ of about $8.1 * 10^{-5} \mathrm{~s}^{-1}$ at $90{ }^{\circ} \mathrm{C}$. At 30 ${ }^{\circ} \mathrm{C}, 50{ }^{\circ} \mathrm{C}$, and $70{ }^{\circ} \mathrm{C}$, the $\mathrm{TEB} / \mathrm{NBu}_{4} \mathrm{I}$ catalyst system exhibits complete selectivity towards the formation of TMC as well with respectively the following first-order rate constants of $9.9^{*} 10^{-6}$, $1.5^{*} 10^{-5}$, and $4.7^{*} 10^{-5} \mathrm{~s}^{-1}$, according to in situ infrared spectroscopy (Figures S9 - S11) combined with ${ }^{1} \mathrm{H}$ NMR characterization. As shown in Figure 1d, the calculated enthalpy $\left(\Delta \mathrm{H}^{\ddagger}\right)$ and entropy of activation $\left(\Delta \mathrm{S}^{\ddagger}\right)$ are respectively equal to $6.7 \pm 1.2 \mathrm{kcal} / \mathrm{mol}$ and $-57 \pm 4 \mathrm{cal} /(\mathrm{mol} \cdot \mathrm{K})$ as indicated by the Eyring plot. As a result, the $\Delta G^{\ddagger}$ value is equal to $27.4 \mathrm{kcal} / \mathrm{mol}$ at $90{ }^{\circ} \mathrm{C}$. 

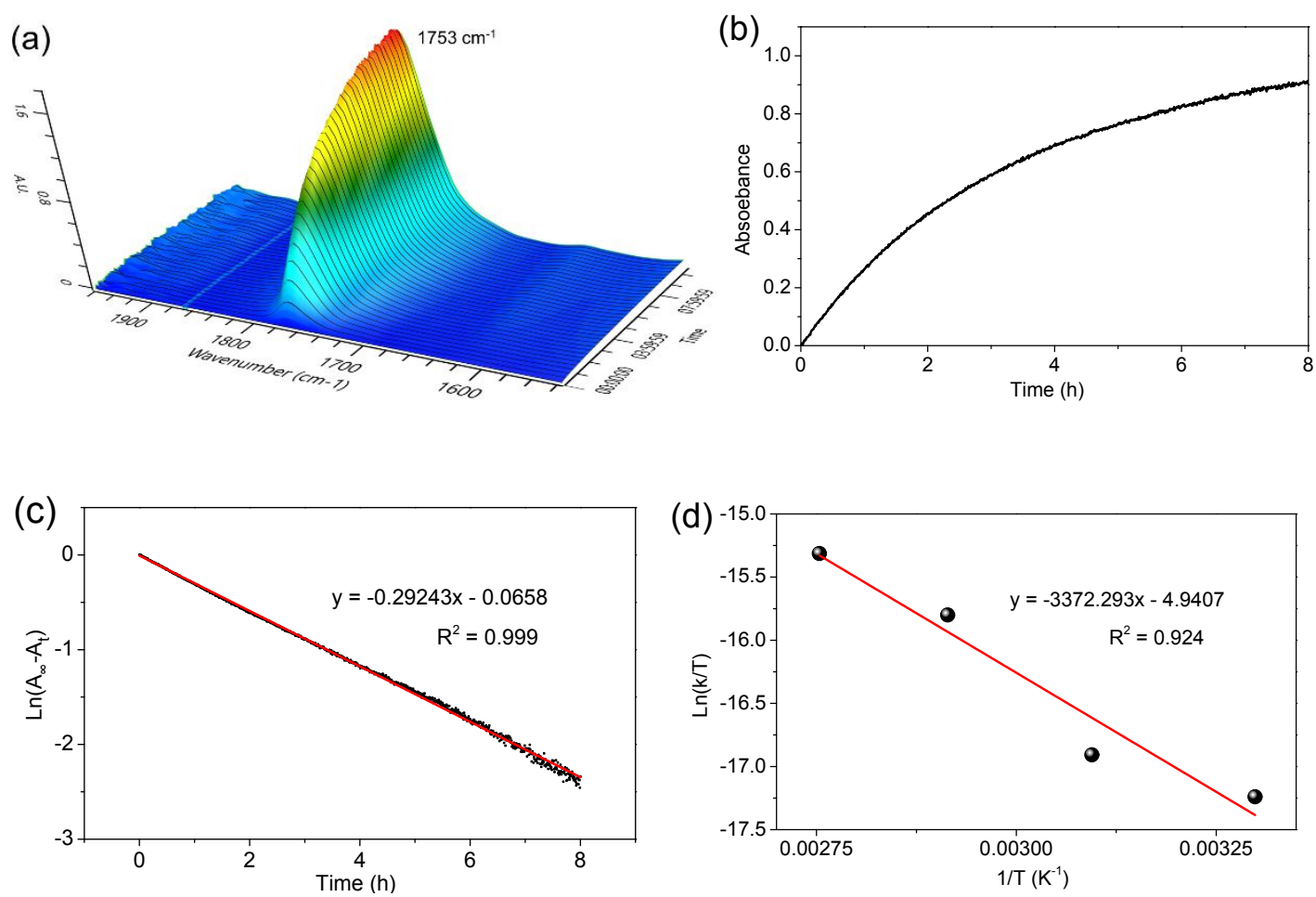

Figure 1. Kinetic studies of the $\mathrm{TMO} / \mathrm{CO}_{2}$ coupling reaction. (a) Three-dimensional stack plot of IR spectra collected every 30 s during the coupling reaction. (b) Reaction profile indicating TMC formation with time. (c) Plot of $\ln \left(A_{\infty}-A_{t}\right) v s$. time, in which $A_{\infty}$ and $A_{t}$ are the absorbances for TMC $\left(1753 \mathrm{~cm}^{-1}\right)$ at time $=$ infinitive and $t$, respectively. (d) Plot of $\ln (\mathrm{k} / \mathrm{T}) v s .1 / \mathrm{T}$ in the range from 30 to $90{ }^{\circ} \mathrm{C}$ for the formation of TMC. Reactions were run with $1 \mathrm{~mL}$ TMO and $1 \mathrm{~mL}$ toluene in a $50 \mathrm{~mL}$ autoclave under 10 bar $\mathrm{CO}_{2}$ pressure and with TMO/TEB/NBu$/$ molar ratio of 100/5/1.

\section{DFT calculations for $\mathrm{TMO} / \mathrm{CO}_{2}$ coupling reaction.}

To verify the idea that both the capping of the growing oxyanions by TEB and also the activation of TMO by TEB are necessary for the $\mathrm{CO}_{2}$ /oxetane coupling to occur selectively, we then performed density functional theory (DFT) calculations to explore the reaction mechanism and origins of its chemoselectivity (computational details are included in the Supplementary Information). The free energy profile of the operative pathway is shown in Figure 2. The reaction 
initiates with the attack of TMO by a weak nucleophile, here the iodide anion. The TEB-activation of TMO plays a significant role in this nucleophilic attack, decreasing the free energy barrier from $43.2 \mathrm{kcal} / \mathrm{mol}$ (TS1) to $23.3 \mathrm{kcal} / \mathrm{mol}$ (TS2) and resulting in the ring-opening of TMO. As expected, TEB forms a borate complex and stabilizes the oxyanion (3); the B-O bond length shortens from $1.781 \AA$ (2) to $1.528 \AA$ (3) (supporting information, Figure S24) characteristic of an ate complex. From 3, three pathways were considered. The nucleophilic attack of $\mathrm{CO}_{2}$ is much more favorable than that of oxetane 1 via TS3 and TEB-activated oxetane (2) ${ }^{[40]}$ The intermediate 4 formed then undergoes a TEB transfer process via TS5 to generate intermediate 5. Subsequently, 5 undergoes an intramolecular cyclization (back-biting) via TS7 to produce the observed product due to the leaving propensity of iodide. The nucleophilic attack by $\mathbf{5}$ of another TEB-activated oxetane was also calculated, but this reaction is less favorable as it requires a much higher energy barrier $(28.1 \mathrm{kcal} / \mathrm{mol}$, TS6). This result can be accounted for in view of the large ionic radius of the iodide ion, of its excellent leaving group ability, and of its polarization. In summary, the nucleophilic iodide anion first attacks TEB-activated oxetane, yielding a TEB stabilized oxyanion via a $\mathrm{B}-\mathrm{O}$ borate bond. After the addition of $\mathrm{CO}_{2}$ through insertion into the $\mathrm{B}-\mathrm{O}$ bond, TMC is produced via a backbiting reaction. 


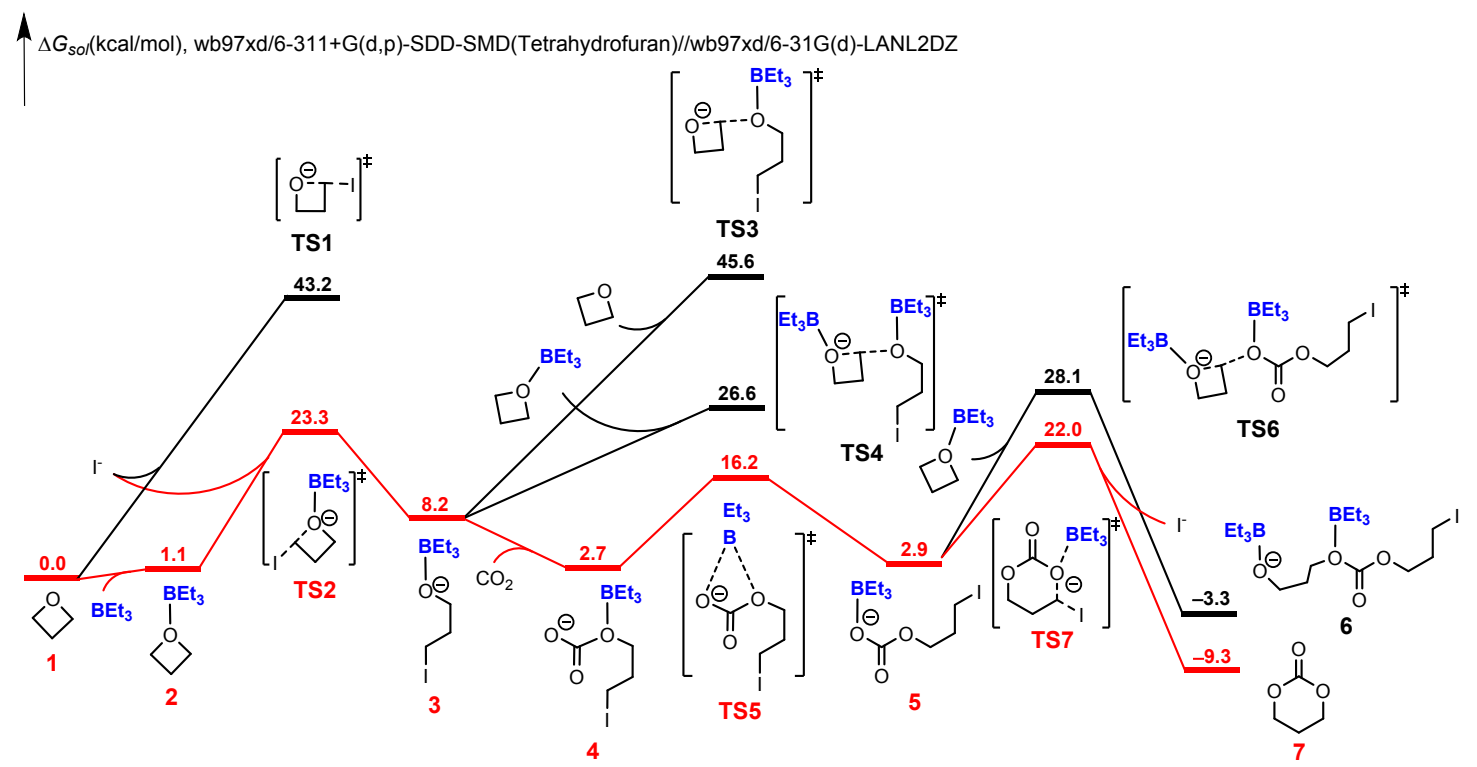

Figure 2. Free energies associated with the coupling reaction of oxetane with $\mathrm{CO}_{2}$ catalyzed by TEB and $\mathrm{I}^{-}$.

The halide-controlled chemoselectivity was further elucidated with DFT calculations. Figure 3 showed the DFT-computed chemoselectivities between polymerization and backbiting reaction with various nucleophilic anions. With bromide ion, the formation of the major product which is TMC (TS9, $22.9 \mathrm{kcal} / \mathrm{mol}$ ) requires a much lower energy barrier compared to that of the minor product which is a linear poly $(\mathrm{TMC})(\mathbf{T S 8}, 26.0 \mathrm{kcal} / \mathrm{mol})$. In contrast, the energy barrier for the TMC generation (TS11, $27.5 \mathrm{kcal} / \mathrm{mol})$ is slightly higher than that of the poly $(\mathrm{TMC})$ formation (TS10, $26.7 \mathrm{kcal} / \mathrm{mol}$ ) when the anion is the chloride anion. This diagram thus suggests that the thermodynamic product in this coupling reaction is the polymer instead of the cyclic carbonate, which is in contrast to what is reported for $\mathrm{CO}_{2}$ /epoxide copolymerization. ${ }^{[41]}$ The computational results are thus fully consistent with the experimental results in Table 1. 


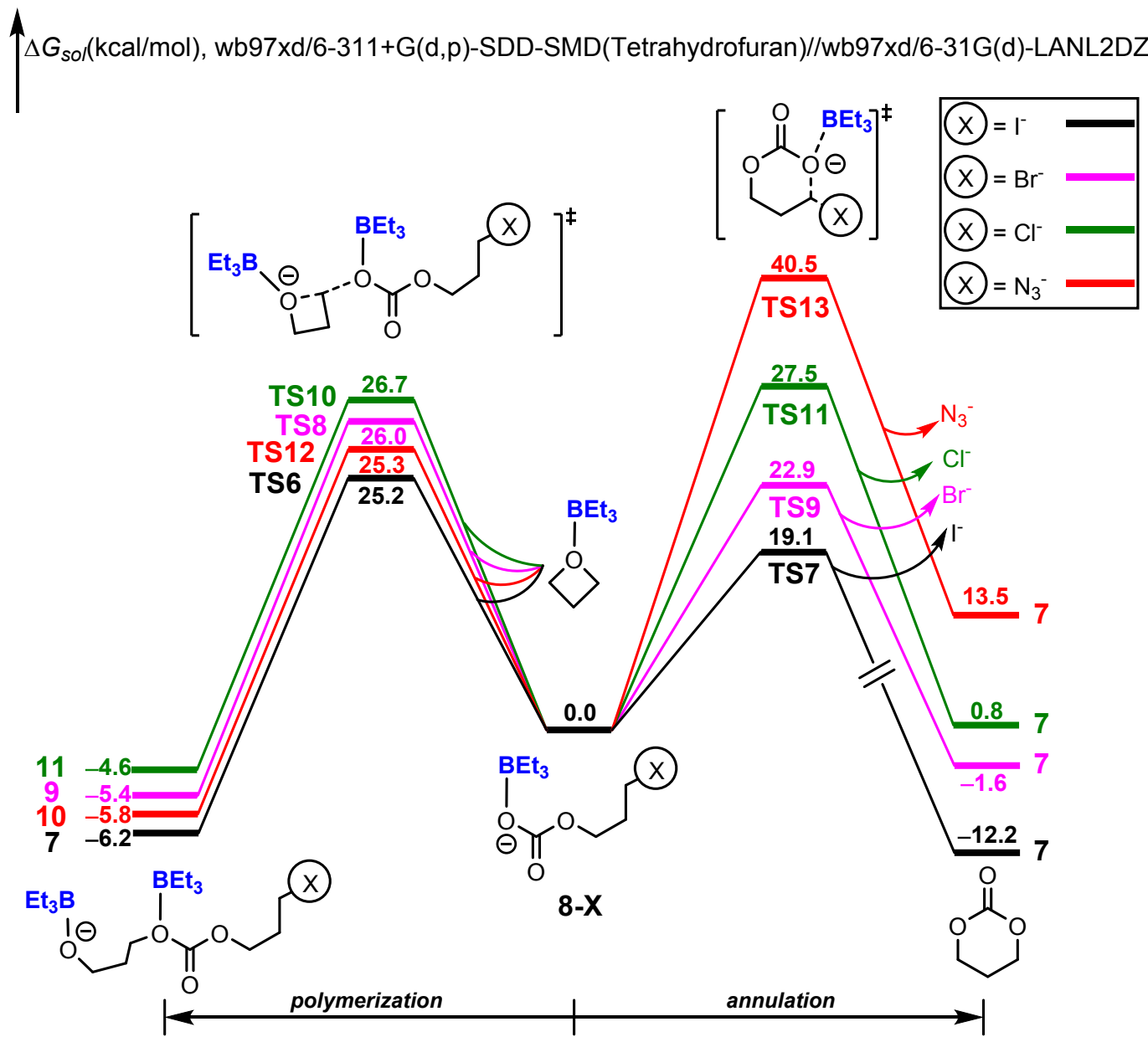

Figure 3. Free energies associated with the oxetane $/ \mathrm{CO}_{2}$ coupling reaction catalyzed by TEB with $\mathrm{I}^{-}, \mathrm{Br}^{-}, \mathrm{Cl}^{-}$, and $\mathrm{N}_{3}^{-}$.

\section{Selective synthesis of poly(TMC) from $\mathrm{CO}_{2}$ and TMO with TEB/N3 ${ }^{-}$.}

It is worthwhile noting that the combination of $\mathrm{TEB}$ and $\mathrm{NBu}_{4} \mathrm{Cl}$ or $\mathrm{PPNCl}$ predominantly affords poly(TMC)s with selectivities of $85 \%$ and $79 \%, M_{\mathrm{n}}$ values of 3.5 and $4.1 \mathrm{~kg} / \mathrm{mol}$, and carbonate contents of $>90 \%$ which is a biocompatible and biodegradable polymer. We then sought to selectively prepare poly(TMC) directly from $\mathrm{TMO}$ and $\mathrm{CO}_{2}$ using an anion with a lower leaving group propensity than chloride. Under 10 bar $\mathrm{CO}_{2}$ pressure at $90{ }^{\circ} \mathrm{C}$ for $24 \mathrm{~h}$, the optimized association of TEB with an ammonium azide salt $\left(\mathrm{NBu}_{4} \mathrm{~N}_{3}\right)$ resulted in the formation of 
poly(TMC) with $>99 \%$ of selectivity for a TMO conversion of $63 \%$ (Figure S12); $\mathrm{N}_{3}{ }^{-}$which has an electronegativity similar to that of $\mathrm{Cl}^{-}$but lower leaving group ability thus favors the propagation reaction at the expense of back-biting reactions. Upon extending the reaction time to $72 \mathrm{~h}$, the TMO conversion grew to $84 \%$, affording a poly(TMC) sample with $94 \%$ of carbonate content and $6 \%$ of ether content according to the ${ }^{1} \mathrm{H}$ and ${ }^{13} \mathrm{C}$ NMR spectra (entry 14 in Table 1 , Figure S13). A $M_{\mathrm{n}}$ of $8.0 \mathrm{~kg} / \mathrm{mol}$ and a dispersity $(\nexists)$ value of 1.5 were obtained by GPC analysis using THF as an eluent and polystyrene standard. The formation of poly(TMC) thus results from the direct copolymerization of TMO with $\mathrm{CO}_{2}$ and not from the ROP of TMC that would have been obtained in an initial step, as the ROP can not occur under the same conditions. This selectivity towards the production of poly(TMC) over TMC is consistent with computational results. As shown in Figure 3, the energy barrier for poly(TMC) formation (TS12, $25.3 \mathrm{kcal} / \mathrm{mol}$ ) is much lower than that of TMC generation (TS13, $40.5 \mathrm{kcal} / \mathrm{mol})$ when the anion is azide anion. Figure 3 also suggests that iodide and bromide based catalysts follow a kinetically controlled pathway whereas the chloride and azide based ones are thermodynamically controlled. Therefore, the use of trialkyl borane combined with azide onium salt gives efficiently access to poly(TMC) starting from $\mathrm{CO}_{2}$ and TMO. In contrast, the formation of poly(TMC) of $<2.0 \mathrm{~kg} / \mathrm{mol}$ when catalyzed by fluorinated alcohols ${ }^{[20]}$ or by metal salen complexes implies the intermediate formation of TMC that subsequently undergoes ring-opening polymerization. ${ }^{[25]}$ This work also significantly departs from the recent contribution of Coulembier, Dove, and their coworkers who obtained poly(carbonate-co-ether) samples by copolymerizing at $105^{\circ} \mathrm{C}$ oxetane with $\mathrm{CO}_{2}$ in the presence of a combination of $I_{2}$ and onium salts. ${ }^{[21,22]}$

The impact of experimental conditions and substituted monomer on $\mathrm{CO}_{2} /$ oxetanes coupling reactions. 
The presence of an excess of TEB is not only beneficial but also essential to the TMO/CO coupling reaction because of the crucial activation of TMO by TEB. For example, upon varying the $[\mathrm{TEB}] /\left[\mathrm{NBu}_{4} \mathrm{I}\right]$ feeding ratio from $3 / 1$ to $1 / 1$, the conversions of oxetane dropped from $70 \%$ to 14\% (entries 1 and 2 in Table 2). Polar solvents also decreased the conversion of TMO into TMC. For instance, the use of dichloromethane (DCM) slowed the TMO conversion of $80 \%$ (entry 3 in Table 2), while toluene which is a solvent of low polarity favored a rather high TMO conversion of $90 \%$ (entry 4 in Table 2). When a coordinating solvent such as THF is used for the coupling reaction, the TMO conversion significantly decreased from $94 \%$ to $47 \%$ (entry 1 in Table 1 versus entry 5 in Table 2), mainly because both THF and TMO compete for the interaction with TEB. One remarkable feature of these TEB-driven processes is their high selectivity toward TMC formation when catalyzed by $\mathrm{TEB} / \mathrm{NBu}_{4} \mathrm{I}$ or towards the formation of linear polycarbonates when initiated by TEB/NBu $\mathrm{N}_{3}$. This indicates the robustness and versatility of the metal-free oxetane$\mathrm{CO}_{2}$ coupling system.

Table 2. Coupling of TMO with $\mathrm{CO}_{2}$ by using $\mathrm{NBu}_{4} \mathrm{I} / \mathrm{TEB}$. [a]

\begin{tabular}{ccccc}
\hline entry & $\begin{array}{c}\text { TEB } \\
(\mathrm{mol} \%)\end{array}$ & solvent & $\begin{array}{c}\text { conv } \\
(\%)^{[\mathrm{b}]}\end{array}$ & $\begin{array}{c}\text { TMC selectivity } \\
(\%)^{[\mathrm{c}]}\end{array}$ \\
\hline 1 & 3 & - & 70 & $>99$ \\
2 & 1 & - & 14 & $>99$ \\
3 & 5 & DCM & 80 & $>99$ \\
4 & 5 & Tol & 90 & $>99$ \\
5 & 5 & THF & 47 & $>99$
\end{tabular}

[a] Reactions were run with TMO and same-volume solvent under 10 bar $\mathrm{CO}_{2}$ pressure at $90{ }^{\circ} \mathrm{C}$ for $8 \mathrm{~h}$, in the presence of $1 \% \mathrm{~mol} \mathrm{NBu}_{4} \mathrm{I}$; [b] TMO conversion; [c] Selectivity of TMC, determined by ${ }^{1} \mathrm{H}$ NMR spectra. 
This method was successfully extended to substituted oxetanes such as 3,3-dimethyl oxetane. Indeed, the success of coupling substituted oxetanes with $\mathrm{CO}_{2}$ with high selectivity and high yield remains challenging. ${ }^{[8,29,32]}$ The reactions were conducted under 10 bar of $\mathrm{CO}_{2}$ at $110{ }^{\circ} \mathrm{C}$. The process exhibited similar characteristics to the above $\mathrm{TMO} / \mathrm{CO}_{2}$ coupling reaction. In the presence of TEB and $\mathrm{NBu}_{4} \mathrm{I}, 3,3$-dimethyl carbonate was successfully obtained with $95 \%$ yield and $>99 \%$ selectivity within $14 \mathrm{~h}$ (entry 1 in Table 3$)$. Nucleophilic bromide salts $\left(\mathrm{NBu}_{4} \mathrm{Br}\right.$ and $\left.\mathrm{NOCt}_{4} \mathrm{Br}\right)$ in combination with TEB also selectively yielded the corresponding cyclic carbonate (entries 2 and 3 in Table 3). Using PPNCl as a nucleophile, both cyclic carbonate and polycarbonate were simultaneously formed with a molar ratio of 38/62 (entry 4 in Table 3). The association of TEB with $\mathrm{NBu}_{4} \mathrm{~N}_{3}$ provided an efficient metal-free route to polycarbonate exhibiting a high selectivity of 95\% (entries 5 and 6 in Table 3, Figure S14). The resulting polycarbonate exhibited a carbonate content of $>99 \%$, a $M_{\mathrm{n}}$ value of $2.3 \mathrm{~kg} / \mathrm{mol}$ and a broad $\doteq$ value of 1.7 after $60 \mathrm{~h}$ of reaction. The reactivity of 3,3-dimethyl oxetane is obviously lower than that of TMO for coupling with $\mathrm{CO}_{2}$, which is consistent with previous studies. ${ }^{[8,20-22]}$

Table 3. Coupling reaction of 3,3-dimethyl oxetane with $\mathrm{CO}_{2}{ }^{[\mathrm{a}]}$

\begin{tabular}{|c|c|c|c|c|c|c|c|c|}
\hline \multirow{2}{*}{ entry } & \multirow{2}{*}{ nucleophile } & \multirow{2}{*}{$\mathrm{t}(\mathrm{h})$} & \multirow{2}{*}{$\begin{array}{l}\text { conv } \\
(\%)^{[b]}\end{array}$} & \multicolumn{2}{|c|}{ selectivity $(\%)^{[\mathrm{c}]}$} & \multirow{2}{*}{$\begin{array}{c}\text { carbonate/ } \\
\text { ether }{ }^{[c]}\end{array}$} & \multirow{2}{*}{$\begin{array}{c}M_{\mathrm{n}} \\
(\mathrm{g} / \mathrm{mol})^{[\mathrm{d}]}\end{array}$} & \multirow{2}{*}{$\bigoplus^{[\mathrm{d}]}$} \\
\hline & & & & $\mathrm{COC}$ & polycarbonate & & & \\
\hline 1 & $\mathrm{NBu}_{4} \mathrm{I}$ & 14 & 95 & $>99$ & - & - & - & - \\
\hline 2 & $\mathrm{NBu}_{4} \mathrm{Br}$ & 21 & 98 & $>99$ & - & - & - & - \\
\hline 3 & $\mathrm{NOCt}_{4} \mathrm{Br}$ & 15 & 95 & $>99$ & - & - & - & - \\
\hline 4 & $\mathrm{PPNCl}$ & 14 & $>99$ & 38 & 62 & - & - & - \\
\hline 5 & $\mathrm{NBu}_{4} \mathrm{~N}_{3}$ & 18 & 46 & 5 & 95 & $>99$ & 2000 & 1.5 \\
\hline 6 & $\mathrm{NBu}_{4} \mathrm{~N}_{3}$ & 60 & 56 & 5 & 95 & $>99$ & 2300 & 1.7 \\
\hline
\end{tabular}


Selectivity of $\mathrm{COC}$ and polycarbonate and carbonate/ether ratio in polycarbonate, determined by ${ }^{1} \mathrm{H}$ NMR spectra; [d] Determined by GPC in tetrahydrofuran (THF) with polystyrene standards;

\section{Selective synthesis of five-membered $\mathrm{COCs}$ from various substituted epoxides and $\mathrm{CO}_{2}$.}

The organocatalytic synthesis of five-membered COC with hydrogen bond donors, ${ }^{[42,43]}$ P-ylide ${ }^{[44]}$ and carbenes ${ }^{[45]}$ have been reported. More recently, Kerton, et al. studied the coupling reaction of propylene oxide and epichlorohydrin with $\mathrm{CO}_{2}$ and demonstrated a high catalytic activity (turnover frequency (TOF) values of $134 \mathrm{~h}^{-1}$ for propylene oxide and $1013 \mathrm{~h}^{-1}$ for glycidyl chloride) when triphenylborane was used. ${ }^{[36]}$ Here, we have also evaluated the potential of the TEB/NBu 4 system as catalyst for the synthesis of five-membered COCs from various substituted epoxides and $\mathrm{CO}_{2}$ (Scheme 3). All of the substrates investigated were converted into the corresponding cyclic carbonates 1a-1i with high selectivity $(>99 \%)$ under mild conditions $\left(90^{\circ} \mathrm{C}, 10\right.$ bar $\left.\mathrm{CO}_{2}\right)$, as shown by the ${ }^{1} \mathrm{H}$ NMR and FT-IR spectra (Figures S15 - S23), demonstrating the versatility of this metalfree system. For most of functionalized epoxides that were subjected to coupling with $\mathrm{CO}_{2}$, even a low loading of TEB $(0.2 \mathrm{~mol} \%)$ and $\mathrm{NBu}_{4} \mathrm{I}(0.4 \mathrm{~mol} \%)$ was effective and of activity comparable to that of metal catalysts, ${ }^{[8]}$ exhibiting TOF values of $42-124 \mathrm{~h}^{-1}$ for 1a-1g five-membered cyclic carbonates. Also, this boron-based system is tolerant of common reactive functions such as alkyl halide, alcohol, ether, and alkene groups. Epoxides characterized by significant steric hindrance, that are known to react sluggishly, ${ }^{[46]}$ when reacted in the same conditions as the other epoxides afforded $\mathbf{1 h}$ and $\mathbf{1 i}$ with $>99 \%$ selectivity and exhibited TOF values in the range of 21 and $14 \mathrm{~h}^{-1}$. On the other hand, we showed in separate works that an epoxide as different as propylene oxide, cyclohexene oxide, phenyl glycidyl ether, styrene oxide, and glycidyl azide could be selectively copolymerized with $\mathrm{CO}_{2}$ into the corresponding polycarbonates using onium salts other than iodide-based ones in association with TEB. ${ }^{[33,47,48]}$ 
Scheme 3. Scope in epoxides. Cyclic carbonates 1a-1i obtained from their corresponding epoxides using $\mathrm{TEB} / \mathrm{NBu}_{4} \mathrm{I}$ as a catalyst system. General conditions: neat, $1 \mathrm{~mL}$ epoxide, molar ratio epoxide/TEB/NBu $4 \mathrm{I}=500 / 1 / 2(\mathbf{1 a - 1 h})$ or 1000/1/10 (1i), $90{ }^{\circ} \mathrm{C}, 4 \mathrm{~h}(\mathbf{1 a - 1 f})$ or $8 \mathrm{~h}(\mathbf{1 g}-\mathbf{1 i}), 10 \mathrm{bar}$ $\mathrm{CO}_{2}$ pressure, $50 \mathrm{~mL}$ autoclave.

\section{CONCLUSIONS}

The synthesis of both six-membered and five-membered COCs by the metal-free coupling of oxetanes with $\mathrm{CO}_{2}$ or that of epoxides with $\mathrm{CO}_{2}$ is described. Carried out under mild conditions, such a coupling process is catalyzed by onium iodide salts associated with trialkyl boranes. The six-membered TMC formed did not undergo concomitantly ring opening polymerization in contrast to the cases of metallic- and other organocatalystic systems reported as the mechanism is totally different. These coupling reactions exhibit high activity and complete selectivity toward the 
formation of COCs, benefiting from the high leaving ability of the iodide anion. The trialkyl borane Lewis acids form borate complexes with the oxyanions and also serve to activate the cyclic ethers (oxetane or epoxide) as clearly demonstrated by computational studies. Upon choosing an onium salt whose anion is not a good leaving group such as $\mathrm{Cl}^{-}$or $\mathrm{N}_{3}^{-}$, the chain growth is favored over back-biting and the formation of polycarbonates ensues. These alkyl borane-mediated systems exhibit high versatility and activity and serve as practicable alternatives to metal catalysts for catalyzing the cycloaddition of cyclic ethers to $\mathrm{CO}_{2}$ and also facilitating the formation of polycarbonates, depending upon the anion used as initiator. In addition, the above-mentioned organocatalysts are commercially available, and trialkyl boranes can be readily oxidized and hydrolyzed into compounds of little toxicity, which can be considered a very convenient and environmentally friendly method. Our ongoing efforts are to design alkyl boranes that could further increase the catalytic activity of the coupling and polymerization processes and to expand the scope of functional cyclic ethers that would be eligible to the above reactions.

\section{AUTHOR INFORMATION}

\section{Corresponding Author}

Xing-Hong Zhang*, xhzhang@zju.edu.cn;

Xin Hong*, hxchem@zju.edu.cn;

Yves Gnanou*, yves.gnanou@kaust.edu.sa;

Xiao-Shuang Feng*, xiaoshuang.feng@kaust.edu.sa.

\section{Author Contributions}


Cheng-Jian Zhang and Shao-Qi Wu made equal contributions to this work. Xing-Hong Zhang, Yves Gnanou and Xiao-Shuang Feng directed the investigations, and revised the manuscript. Cheng-Jian Zhang carried out all experiments and analyses, and wrote the draft. Senthil Boopathi carried out some experiments and analyses. Shao-Qi Wu and Xin Hong carried out DFT calculations and revised the manuscript.

\section{SUPPORTING INFORMATION}

The Supporting Information is available free of charge at https://pubs.acs.org/doi/.

Experimental materials; experimental methods; experimental procedure; ${ }^{1} \mathrm{H} N M R$ spectra; IR spectra; and computational study

\section{ACKNOWLEDGMENT}

Xing-Hong Zhang gratefully acknowledges the financial support of the National Science Foundation of the People's Republic of China (no. 51973190 and 21774108). Xin Hong is grateful for financial support from the National Natural Science Foundation of China (21702182, 21873081) and the Fundamental Research Funds for the Central Universities (2-2050205-19361). Cheng-Jian Zhang acknowledges the support of KAUST for his stay in Gnanou's laboratory.

\section{REFERENCES}

[1]. Zhu, Y.; Romain, C.; Williams, C. K. Sustainable polymers from renewable resources. Nature 2016, 540, 354. DOI: 10.1038/nature21001

[2]. Sanz-Pérez, E. S.; Murdock, C. R.; Didas, S. A.; Jones, C. W. Direct capture of $\mathrm{CO}_{2}$ from ambient air. Chem. Rev. 2016, 116, 11840-11876. DOI: 10.1021/acs.chemrev.6b00173 
[3]. Aresta, M.; Dibenedetto, A.; Angelini, A. Catalysis for the valorization of exhaust carbon: from $\mathrm{CO}_{2}$ to chemicals, materials, and fuels. Technological use of $\mathrm{CO}_{2}$. Chem. Rev. 2014, 114, 1709-1742. DOI: $10.1021 / \mathrm{cr} 4002758$

[4]. Artz, J.; Müller, T. E.; Thenert, K.; Kleinekorte, J.; Meys, R.; Sternberg, A.; Bardow, A.; Leitner, W. Sustainable conversion of carbon dioxide: An integrated review of catalysis and life cycle assessment. Chem. Rev. 2018, 118, 434-504. DOI: 10.1021/acs.chemrev.7b00435

[5]. Von der Assen, N.; Jung, J.; Bardow, A. Life-cycle assessment of carbon dioxide capture and utilization: avoiding the pitfalls. Energy Environ. Sci. 2013, 6, 2721-2734. DOI: 10.1039/C3EE41151F

[6]. Yang, Z.-Z.; He, L.-N.; Gao, J.; Liu, A.-H.; Yu, B. Carbon dioxide utilization with C-N bond formation: carbon dioxide capture and subsequent conversion. Energy Environ. Sci. 2012, 5, 6602-6639. DOI: 10.1039/C2EE02774G

[7]. Lu, X.-B.; Ren, W.-M.; Wu, G.-P. $\mathrm{CO}_{2}$ copolymers from epoxides: Catalyst activity, product selectivity, and stereochemistry control. Acc. Chem. Res. 2012, 45, 1721-1735. DOI: $10.1021 / \operatorname{ar} 300035 \mathrm{z}$

[8]. Martín, C.; Fiorani, G.; Kleij, A. W. Recent advances in the catalytic preparation of cyclic organic carbonates. ACS Catal. 2015, 5, 1353-1370. DOI: 10.1021/cs5018997

[9]. Subramanian, S.; Oppenheim, J.; Kim, D.; Nguyen, T. S.; Silo, W. M. H.; Kim, B.; Goddard, W. A.; Yavuz, C. T. Catalytic non-redox carbon dioxide fixation in cyclic carbonates. Chem 2019, 5, 3232-3242. DOI: 10.1016/j.chempr.2019.10.009

[10]. Coates, G. W.; Moore, D. R. Discrete metal-based catalysts for the copolymerization of $\mathrm{CO}_{2}$ and epoxides: Discovery, reactivity, optimization, and mechanism. Angew. Chem. Int. Ed. 2004, 43, 6618-6639. DOI: 10.1002/anie.200460442

[11]. Darensbourg, D. J. Making plastics from carbon dioxide: Salen metal complexes as catalysts for the production of polycarbonates from epoxides and $\mathrm{CO}_{2}$. Chem. Rev. 2007, 107, 2388-2410. DOI: $10.1021 / \mathrm{cr} 068363 \mathrm{q}$

[12]. Li, Y.; Zhang, Y.-Y.; Hu, L.-F.; Zhang, X.-H.; Du, B.-Y.; Xu, J.-T. Carbon dioxide-based copolymers with various architectures. Prog. Polym. Sci. 2018, 82, 120-157. DOI: 10.1016/j.progpolymsci.2018.02.001 
[13]. Wei, X.; Xu, W.; Vijayakumar, M.; Cosimbescu, L.; Liu, T.; Sprenkle, V.; Wang, W. TEMPO-based catholyte for high-energy density nonaqueous redox flow batteries. Adv. Mater. 2014, 26, 7649-7653. DOI: 10.1002/adma.201403746

[14]. Schäffner, B.; Schäffner, F.; Verevkin, S. P.; Börner, A. Organic carbonates as solvents in synthesis and catalysis. Chem. Rev. 2010, 110, 4554-4581. DOI: 10.1021/cr900393d

[15]. Kim, S. H.; Kim, K. H.; Hong, S. H. Carbon dioxide capture and use: Organic synthesis using carbon dioxide from exhaust gas. Angew. Chem. Int. Ed. 2014, 53, 771-774. DOI: 10.1002/anie.201308341

[16]. Laserna, V.; Fiorani, G.; Whiteoak, C. J.; Martin, E.; Escudero-Adán, E.; Kleij, A. W. Carbon dioxide as a protecting group: Highly efficient and selective catalytic access to cyclic cis-diol scaffolds. Angew. Chem. Int. Ed. 2014, 53, 10416-10419. DOI: 10.1002/anie. 201406645

[17]. Zhang, H.; Liu, H.-B.; Yue, J.-M. Organic carbonates from natural sources. Chem. Rev. 2014, 114, 883-898. DOI: 10.1021/cr300430e

[18]. Alagi, P.; Ghorpade, R.; Choi, Y. J.; Patil, U.; Kim, I.; Baik, J. H.; Hong, S. C. Carbon Dioxide-Based Polyols as Sustainable Feedstock of Thermoplastic Polyurethane for Corrosion-Resistant Metal Coating. ACS Sustainable Chem. Eng. 2017, 5, 3871-3881. DOI: 10.1021/acssuschemeng.6b03046

[19]. Wang, J.; Zhang, H.; Miao, Y.; Qiao, L.; Wang, X.; Wang, F. Waterborne polyurethanes from $\mathrm{CO}_{2}$ based polyols with comprehensive hydrolysis/oxidation resistance. Green Chem. 2016, 18, 524-530. DOI: $10.1039 / \mathrm{c} 5 \mathrm{gc} 01373 \mathrm{a}$

[20]. Alves, M.; Grignard, B.; Boyaval, A.; Méreau, R.; De Winter, J.; Gerbaux, P.; Detrembleur, C.; Tassaing, T.; Jérôme, C. Organocatalytic coupling of $\mathrm{CO}_{2}$ with oxetane. ChemSusChem 2017, 10, 1128-1138. DOI: 10.1002/cssc.201601185

[21]. Huang, J.; De Winter, J.; Dove, A. P.; Coulembier, O. Metal-free synthesis of poly(trimethylene carbonate) by efficient valorization of carbon dioxide. Green Chem. 2019, 21, 472-477. DOI: 10.1039/c8gc03607a

[22]. Huang, J.; Jehanno, C.; Worch, J. C.; Ruipérez, F.; Sardon, H.; Dove, A. P.; Coulembier, O. Selective organocatalytic preparation of trimethylene carbonate from oxetane and carbon dioxide. ACS Catal. 2020, 5399-5404. DOI: 10.1021/acscatal.0c00689 
[23]. Darensbourg, D. J.; Moncada, A. I. (Salen)Co(II) $/ n-\mathrm{Bu}_{4} \mathrm{NX}$ catalysts for the coupling of $\mathrm{CO}_{2}$ and oxetane: Selectivity for cyclic carbonate formation in the production of poly(trimethylene carbonate). Macromolecules 2009, 42, 4063-4070. DOI: 10.1021/ma9002006

[24]. Darensbourg, D. J.; Choi, W.; Ganguly, P.; Richers, C. P. Biometal derivatives as catalysts for the ring-opening polymerization of trimethylene carbonate. Optimization of the $\mathrm{Ca}(\mathrm{II})$ Salen catalyst system. Macromolecules 2006, 39, 4374-4379. DOI: 10.1021/ma0603433

[25]. Darensbourg, D. J.; Moncada, A. I.; Choi, W.; Reibenspies, J. H. Mechanistic studies of the copolymerization reaction of oxetane and carbon dioxide to provide aliphatic polycarbonates catalyzed by (Salen)CrX complexes. J. Am. Chem. Soc. 2008, 130, 6523-6533. DOI: $10.1021 / \mathrm{ja} 800302 \mathrm{c}$

[26]. Lee, J.-C.; Litt, M. H. Ring-opening polymerization of ethylene carbonate and depolymerization of poly(ethylene oxide-co-ethylene carbonate). Macromolecules 2000, 33, 1618-1627. DOI: 10.1021/ma9914321

[27]. Felder, S. E.; Redding, M. J.; Noel, A.; Grayson, S. M.; Wooley, K. L. Organocatalyzed ROP of a glucopyranoside derived five-membered cyclic carbonate. Macromolecules 2018, 51, 1787-1797. DOI: 10.1021/acs.macromol.7b01785

[28]. Kamber, N. E.; Jeong, W.; Waymouth, R. M.; Pratt, R. C.; Lohmeijer, B. G. G.; Hedrick, J. L. Organocatalytic ring-opening polymerization. Chem. Rev. 2007, 107, 5813-5840. DOI: $10.1021 / \mathrm{cr} 068415 \mathrm{~b}$

[29]. Rintjema, J.; Guo, W.; Martin, E.; Escudero-Adán, E. C.; Kleij, A. W. Highly chemoselective catalytic coupling of substituted oxetanes and carbon dioxide. Chem. - Eur. J. 2015, 21, 10754-10762. DOI: 10.1002/chem.201501576

[30]. Whiteoak, C. J.; Martin, E.; Belmonte, M. M.; Benet-Buchholz, J.; Kleij, A. W. An efficient iron catalyst for the synthesis of five- and six-membered organic carbonates under mild conditions. Adv. Synth. Catal. 2012, 354, 469-476. DOI: 10.1002/adsc.201100752

[31]. Whiteoak, C. J.; Kielland, N.; Laserna, V.; Escudero-Adán, E. C.; Martin, E.; Kleij, A. W. A powerful aluminum catalyst for the synthesis of highly functional organic carbonates. $J$. Am. Chem. Soc. 2013, 135, 1228-1231. DOI: 10.1021/ja311053h

[32]. Darensbourg, D. J.; Horn Jr, A.; Moncada, A. I. A facile catalytic synthesis of trimethylene carbonate from trimethylene oxide and carbon dioxide. Green Chem. 2010, 12, 1376-1379. DOI: $10.1039 / \mathrm{c} 0 \mathrm{gc} 00136 \mathrm{~h}$ 
[33]. Zhang, D.; Boopathi, S. K.; Hadjichristidis, N.; Gnanou, Y.; Feng, X. Metal-free alternating copolymerization of $\mathrm{CO}_{2}$ with epoxides: Fulfilling "green" synthesis and activity. J. Am. Chem. Soc. 2016, 138, 11117-11120. DOI: 10.1021/jacs.6b06679

[34]. Achiral B(III) Lewis Acids. In Lewis Acids in Organic Synthesis; pp 89-133. DOI: 10.1002/9783527618309.ch4

[35]. Chiral B(III) Lewis Acids. In Lewis Acids in Organic Synthesis; pp 135-190. DOI: 10.1002/9783527618309.ch4

[36]. Andrea, K. A.; Kerton, F. M. Triarylborane-catalyzed formation of cyclic organic carbonates and polycarbonates. ACS Catal. 2019, 9, 1799-1809. DOI: $10.1021 /$ acscatal.8b04282

[37]. Stephan, D. W. Frustrated lewis pairs. J. Am. Chem. Soc. 2015, 137, 10018-10032. DOI: $10.1021 /$ jacs.5b06794

[38]. Berkefeld, A.; Piers, W. E.; Parvez, M. Tandem frustrated Lewis pair/tris(pentafluorophenyl)borane-catalyzed deoxygenative hydrosilylation of carbon dioxide. J. Am. Chem. Soc. 2010, 132, 10660-10661. DOI: 10.1021/ja105320c

[39]. Li, Z.; Zhang, L.; Nishiura, M.; Luo, G.; Luo, Y.; Hou, Z. $\mathrm{CO}_{2}$ activation by Lewis pairs generated under copper catalysis enables difunctionalization of imines. J. Am. Chem. Soc. 2020, 142, 1966-1974. DOI: 10.1021/jacs.9b11423

[40]. The transition state between intermediates 3 and 4 was not located despite extensive efforts. Energy scan along the C-O bond formation showed no electronic energy barrier.

[41]. Darensbourg, D. J.; Yarbrough, J. C.; Ortiz, C.; Fang, C. C. Comparative kinetic studies of the copolymerization of cyclohexene oxide and propylene oxide with carbon dioxide in the presence of chromium salen derivatives. In situ FTIR measurements of copolymer vs cyclic carbonate production. J. Am. Chem. Soc. 2003, 125, 7586-7591. DOI: 10.1021/ja034863e

[42]. Sopeña, S.; Martin, E.; Escudero-Adán, E. C.; Kleij, A. W. Pushing the Limits with Squaramide-Based Organocatalysts in Cyclic Carbonate Synthesis. ACS Catalysis 2017, 7 , 3532-3539. DOI: 10.1021/acscatal.7b00475

[43]. Arayachukiat, S.; Kongtes, C.; Barthel, A.; Vummaleti, S. V. C.; Poater, A.; Wannakao, S.; Cavallo, L.; D’Elia, V., Ascorbic Acid as a Bifunctional Hydrogen Bond Donor for the Synthesis of Cyclic Carbonates from $\mathrm{CO}_{2}$ under Ambient Conditions. ACS Sustain. Chem. Eng. 2017, 5, 6392-6397. DOI: 10.1021/acssuschemeng.7b01650 
[44]. Wang, L.; Zhang, G.; Kodama, K.; Hirose, T., An efficient metal- and solvent-free organocatalytic system for chemical fixation of $\mathrm{CO}_{2}$ into cyclic carbonates under mild conditions. Green Chem. 2016, 18, 1229-1233. DOI: 10.1039/c5gc02697k

[45]. Zhou, H.; Wang, G.-X.; Zhang, W.-Z.; Lu, X.-B., $\mathrm{CO}_{2}$ Adducts of Phosphorus Ylides: Highly Active Organocatalysts for Carbon Dioxide Transformation. ACS Catalysis 2015, 5, 6773-6779. DOI: 10.1021/acscatal.5b01409

[46]. Kember, M. R.; Buchard, A.; Williams, C. K. Catalysts for $\mathrm{CO}_{2}$ /epoxide copolymerisation. Chem. Commun. 2011, 47, 141-163. DOI: 10.1039/C0CC02207A

[47]. Boopathi, S. K.; Hadjichristidis, N.; Gnanou, Y.; Feng, X. Direct access to poly(glycidyl azide) and its copolymers through anionic (co-)polymerization of glycidyl azide. Nat. Commun. 2019, 10, 293. DOI: 10.1038/s41467-018-08251-1

[48]. Chen, Z.; Yang, J.-L.; Lu, X.-Y.; Hu, L.-F.; Cao, X.-H.; Wu, G.-P.; Zhang, X.-H. Triethyl borane-regulated selective production of polycarbonates and cyclic carbonates for the coupling reaction of $\mathrm{CO}_{2}$ with epoxides. Polym. Chem. 2019, 10, 3621-3628. DOI:

10.1039/C9PY00398C

For TOC only:

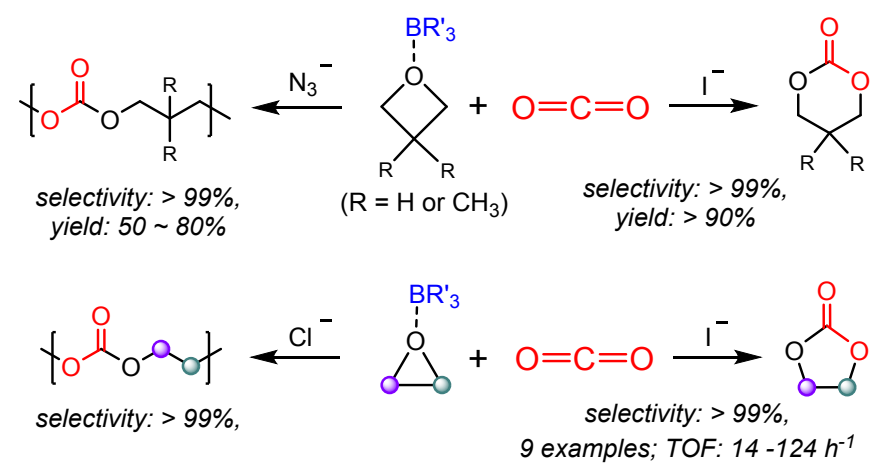

Synopsis: The metal-free boron-based catalysts achieve the selective synthesis of cyclic carbonates and polycarbonates from the sustainable process of the epoxide and $\mathrm{CO}_{2}$ coupling reaction. 